\title{
Research on the Effect of ETCI Based HCCI Technology in the Best Fuel Area
}

\author{
Youcheng Sun*, Lei Shi, Yong Gui and Kangyao Deng \\ Key Laboratory for Power Machinery and Engineering of Ministry of Education, Shanghai Jiao Tong University, \\ Shanghai 200240, China
}

\begin{abstract}
Exhaust check point injection compression ignition (ETCI), the trapped promote internal thermal residues high temperature high pressure jet fuel mixture is one of the most effective methods to achieve homogeneous charge compression ignition (HCCI). This paper is based on the ETCI combustion mode to study the effect of timing heating of the exhaust valve and the cooling effect of the pressure on the combustion process.. Results show that the best fuel economy can start injection of Ca BTDC at $1500 \mathrm{r} / \mathrm{min}$, the exhaust valve timing on combustion properties are strongly influenced by the 370, Shan'xi. Using the residual gas coefficient of the exhaust valve timing control, the combustion stage can be controlled indirectly by the intake temperature of the cylinder. In addition, constant pressure, inlet pressure increasing can increase the excess air coefficient decrease the mixture of average air temperature, which can also be control as the key parameters of the combustion phase in some areas. Therefore, the reasonable cooperation between the exhaust valve timing and the pressure pressure can effectively control the combustion process and emission minimization. At $1500 \mathrm{r} / \mathrm{min}, 30$ (calcium negative valve overlap (NVO) and $0.18 \mathrm{MPa}$ pressure, the limit of low load and high load limit of HCCI combustion can be reached $0.27 \mathrm{MPa}$ and $0.723 \mathrm{MPa}$, respectively.
\end{abstract}

Keywords: Diesel engine, HCCI, load extension, NVO, supercharging.

\section{INTRODUCTION}

It has been proved that homogeneous charge compression ignition (HCCI) has a great potential for reducing NOx and PM emissions while providing high thermal efficiency [1-3]. However, HCCI engines still encounter many difficulties such as it being easy to misfire at low loads and difficult to form a premixedhomogeneous charge, control the combustion phase, andoperate at high loads. [4-6]. Therefore, determining how to solve these technical problems has been the research focus in the practical application of HCCI engines $[7,8]$.

The negative valve overlap (NVO), which is achieved by the early closing of the exhaust valve and the late opening of the inlet valve, can be used to change the amount and temperature of the exhaust gas in the cylinder [9].

To date, most of the studies on the NVO have focused on gasoline engines. The combined effects of boosting, intake air temperature, trapped residual gas fraction, and dilution on the maximum pressure rise rate (MPRR) was investigated in a boosted single cylinder gasoline HCCI engine with combustion controlled by negative valve overlap [10]. Weall et al. enabled the lowest load point of $160 \mathrm{kPa}$ indicated mean effective pressure (IMEP) using a valve deactivation strategy, making it more compatible for production-intent platforms [11]. Hunicz et al. achieved better performance of combustion using the NVO and split injection in a CAI gasoline engine $[12,13]$.
Because diesel fuel is more difficult to vaporize, the NVO can be applied to diesel HCCI engines [14]. The stronger turbulence intensity and higher temperature homogeneity with higher NVO improve fuel vaporization and airfuel mixing.

However, only a few researchers have focused on the NVO technique on diesel engines. A three-dimensional simulation was applied to investigate the effects of negative valve overlap on the gas exchange processes and mixture and temperature distributions in a diesel HCCI engine with early in-cylinder injection [15]. The result indicated that enlarged NVO not only increased the in-cylinder temperature but also improved the temperature homogeneity.

A previous study demonstrated that the technique of exhaust top dead center injection compression ignition (ETCI) is one of the most effective methods to realize HCCI combustion [14]. This method uses high temperature residuals produced by NVO to help vaporize diesel fuel and promote mixing. A large amount of high temperature gas could reduce fuel wall wetting but cause an over advanced combustion phase and an over rapid burn rate, and the operation is limited at low loads.

In order to overcome the limitation of the operating range of the diesel HCCI, the air pressure method is increased.. Thus, a wider range of operation is achieved compared with the natural inspiratory condition because the relatively complete combustion occurs because more air is utilized under these conditions [16]. In addition, the increase in the intake pressure of hydrocarbons and carbon monoxide emissions due to higher oxygen rate. Han et al. The operating range of LTC is in performance and exhaust gas emissions.. The operating range of cryogenic diesel combustion increases with 
the intake pressure and the higher injection pressure promotes the expansion. In addition, the exhaust gas emissions include hydrocarbon, carbon monoxide, soot emissions and natural air suction conditions compared to lower the lowtemperature combustion.

In this study, the authors extended the load range of a diesel HCCI engine by combining the control strategy of variable exhaust valve timing with inlet boosting and researched the effects of NVO and supercharging on combustion performance, load range, and emissions.

\section{EXPERIMENTAL SETUP}

The experiment was performed on a naturally aspirated, single-cylinder 135 diesel engine. Table 1 lists the basic parameters of the engine. To achieve better injection strategies, a common-rail fuel injection system whose maximum injection pressure could be raised as high as $160 \mathrm{MPa}$ was attached. In addition, the engine was equipped with a simulated supercharging system whose maximum boost pressure could reach $0.8 \mathrm{MPa}$ and a VVT mechanism which could realize inlet and exhaust valve regulation by $40{ }^{\circ} \mathrm{CA}$. As $\mathrm{HCCI}$ combustion is sensitive to the temperature of cooling water, the experiment controlled the lubricating oil temperature at $70 \pm 1{ }^{\circ} \mathrm{C}$ and cooling water temperature at $80 \pm 1{ }^{\circ} \mathrm{C}$ using an oil and water temperature control system.

Table 1. Parameters of the test engine.

\begin{tabular}{|c|c|}
\hline Engine base type & Direct-injection, single-cylinder \\
\hline \hline Cycle & 4 stroke \\
\hline Number of valves & 4 \\
\hline Bore $/ \mathrm{mm}$ & 135 \\
\hline Stroke $/ \mathrm{mm}$ & 150 \\
\hline Displacement volume / cm3 & 2147 \\
\hline Compression ratio & $14.8: 1$ \\
\hline Nozzle design & $\Phi 0.20$ mm $\times 7$ holes, \\
\hline Spray included angle & $150^{\circ}$ \\
\hline Boost control & External Simulated boosting \\
\hline Valve timing & Variable (manually) \\
\hline
\end{tabular}

Fig. (1) presents a schematic of the experimental setup for the single cylinder diesel engine. The engine was coupled to a DC dynamometer, which could keep the engine operating at a set speed. The cylinder was fitted with a Kistler6125B piezoelectric pressure transducer and the output signals were amplified with a Kistler5011.AVLDiGas 4000 gas analyzer. In addition, an AVL439opacimeterwas used for the exhaust emission measurements.

Fig. (2) illustrates the simple structure of our VVT system. The valve timing was adjusted by changing the axial distance between bevel wheell and bevel wheel 2.The timing of the inlet and exhaust valves was set manually. As the distance was limited by the mechanism structure, the operation range of valve timing varied from 0 to $40^{\circ} \mathrm{CA}$. In the research, the exhaust valve timing was defined by the exhaust valve closure (EVC).

A simulated supercharging system was adopted in the research. The intake boost pressure was controlled by a valve before a surge tank, and the exhaust pressure was uncontrolled. Compressed air was produced by an air compressor which could provide at most $0.8 \mathrm{MPa}$ (gauge) pressure. The inlet pressure could be adjusted from 0 to $0.3 \mathrm{MPa}$ (gauge).

The fuel was injected into the cylinder in the NVO period. By closing the exhaust valve early and opening the inlet valve late, the residual gas in the cylinder heated the mixture to promote the vaporization of the diesel.

In the experiment, the engine speed was fixed at $1500 \mathrm{r} / \mathrm{min}$, and the common rail pressure was $80 \mathrm{MPa}$. For HCCI combustion, we first optimized the injection timing and then researched the effect of various levels of NVO and boost pressure on the load extension and emission characteristic of HCCI combustion under the fixed optimum injection timing. Because the exhaust pressure was not adjusted, we used the gross indicated mean effective pressure (IMEP ${ }_{\mathrm{g}}$ ) as the comparison parameter for the engine load to eliminate the effect of simulated supercharging on the pumping power.

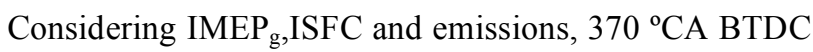
was confirmed as the optimal start of injection timing for $\mathrm{HCCI}$ in the following experiments.

\section{EXPERIMENTALRESULTS AND DISCUSSION}

\subsection{Effects of EVC and Supercharging on Internal Ex- haust Gas Recycling (IEGR) and Tive}

The engine speed was maintained at $1500 \mathrm{r} / \mathrm{min}$, the fuel injection pressure was maintained at $80 \mathrm{MPa}$, the injection fuel quantity per-cycle was maintained at $0.0585 \mathrm{~g}$, and IVO was maintained at $380^{\circ} \mathrm{CA}$ ATDC. The boost pressure was adjusted in steps of $0.02 \mathrm{MPa}$.

\subsubsection{Effects of EVC and Supercharging on IEGR}

Fig. (3) shows the effects of EVC and boost pressure(gauge) on the residual gas fraction (RGF) and the excess air ratio $\alpha$. When the boost pressure was maintained at 0 $\mathrm{MPa}$ and EVC varied from $350^{\circ} \mathrm{CA}$ ATDC to $330^{\circ} \mathrm{CA}$ ATDC, the RGF increased from $5.88 \%$ to $13.27 \%$. EVC had a significant effect on the RGF. Increasing the boost pressure caused the in-cylinder fresh charge to increase rapidly; however, the exhaust back pressure was kept constant, and the total mass of residuals did not change distinctly; thus, the RGF was slightly reduced. When EVC was maintained at $330^{\circ} \mathrm{CA}$ ATDC and the boost pressure was adjusted from 0 $\mathrm{MPa}$ to $0.08 \mathrm{MPa}$, the RGF decreased from $13.27 \%$ to $10.89 \%$. Thus, it could be observed that EVC had a greater effect on the RGF than the boost pressure.

The injection fuel quantity was kept constant, and the excess air ratio $\alpha$ was mainly determined by the amount of incylinder fresh charge. When EVC was maintained at $350^{\circ}$ CA ATDC, $\alpha$ was the largest at a constant boost pressure. By advancing EVC from $350^{\circ} \mathrm{CA}$ ATDC to $330^{\circ} \mathrm{CA}$ ATDC, $\alpha$ gradually decreased from 3.081 to 2.461 when the boost 


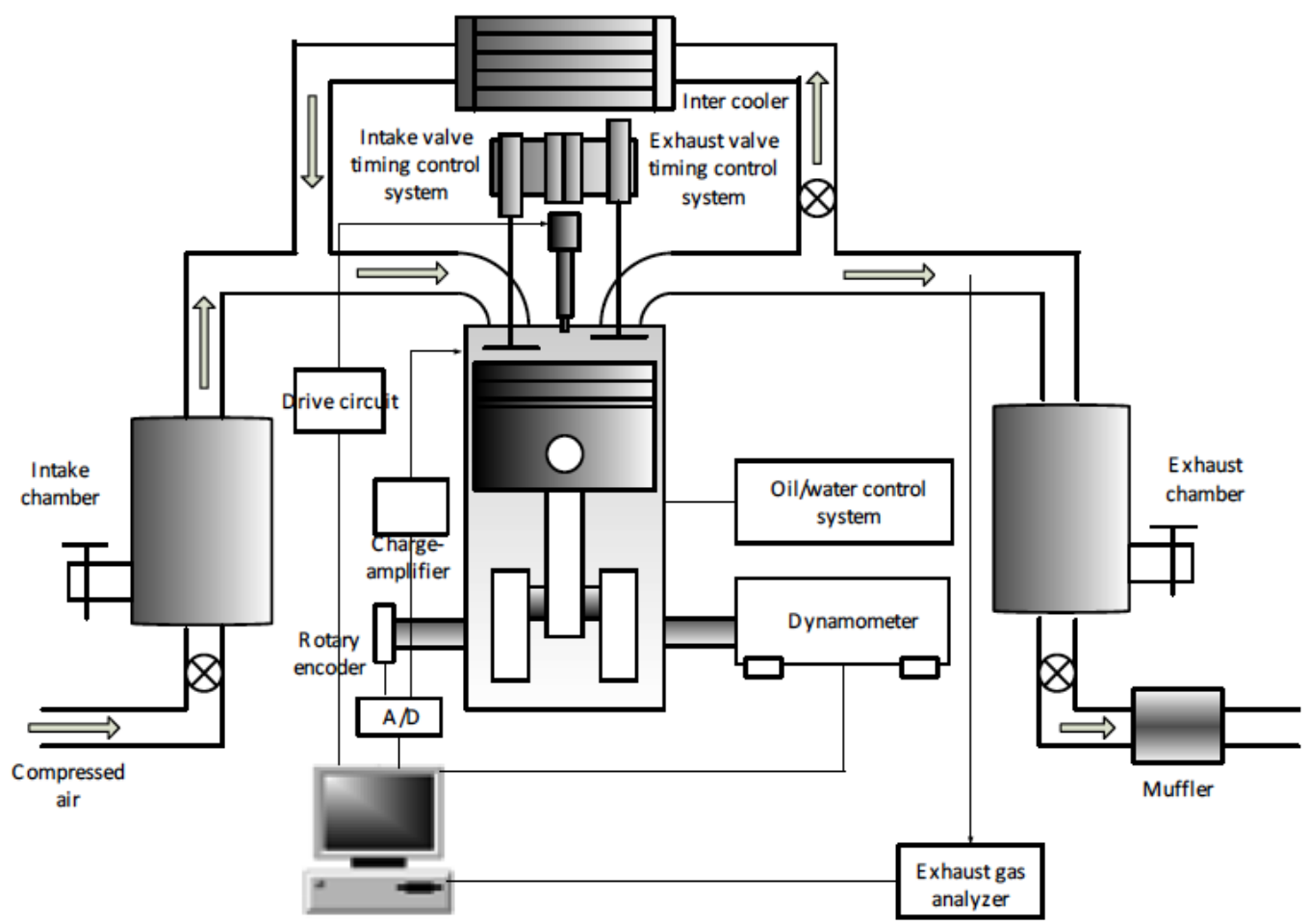

Fig. (1). Schematic diagram of the test system.

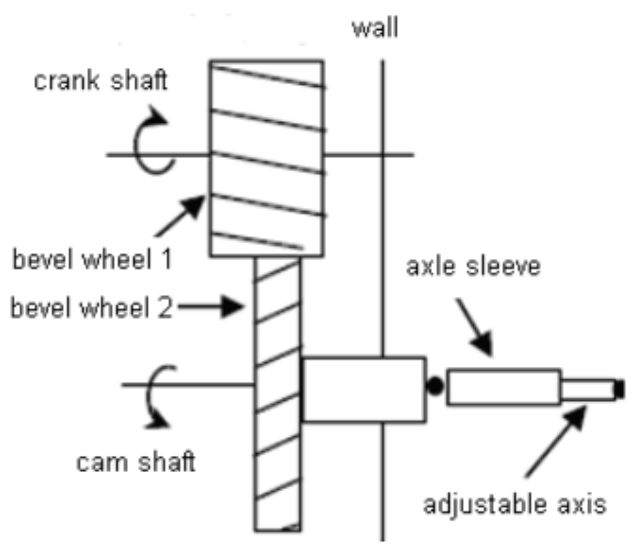

Fig. (2). VVT system.

pressure was $0 \mathrm{MPa}$ because the amount of trapped residuals increased when the fresh charge amount decreased. A higher boost pressure increased the density of intake air and the total mass of charge in the cylinder. There was a wide variation of $\alpha$ over the range of boost pressure. $\alpha$ reached the maximum value of 5.814 at the highest boost pressure. The effect of the boost pressure on $\alpha$ is larger than that of EVC on $\alpha$.

\subsubsection{Effects of EVC and Supercharging on Tivc}

$T_{\text {ivc }}$ (the mean intake temperature at the IVC moment) is one of the most important factors for HCCI combustion characteristics. Because of the existence of $\mathrm{NVO}$, internal residuals were trapped in the cylinder. High temperature residuals heated cool fresh charge, and the volume efficiency decreased. As EVC advanced, the amount of residual gases increased. More residual gases heated more fresh charge, and

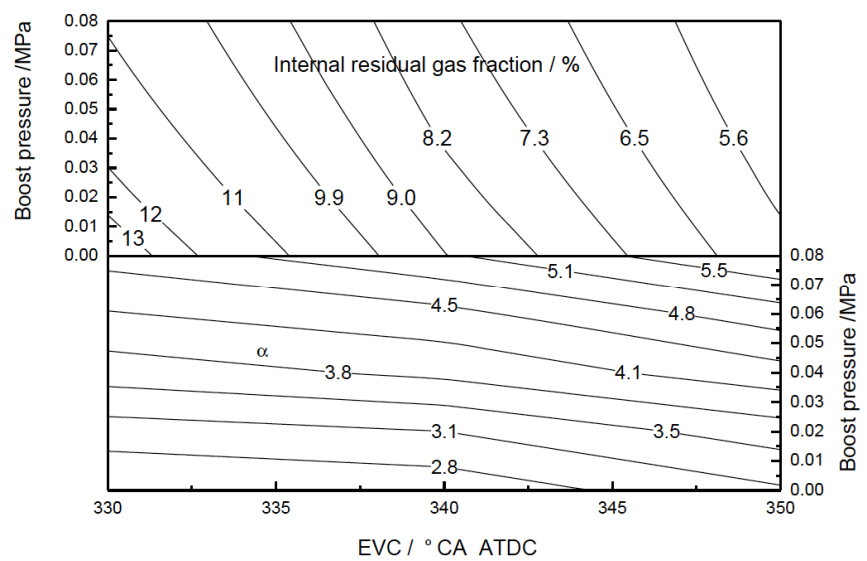

Fig. (3). Effects of EVC and boost pressure (gauge) on IEGR.

the mean temperature of mixing charge increased. Supercharging caused more fresh charge to enter the cylinder. However, EVC was kept constant and the amount of residuals varied little; thus, the percent of cool charge increased, and $T_{\mathrm{ivc}}$ declined.

Fig. (4) illustrates the effects of EVC and boost pressure(gauge) on $T_{\mathrm{ivc}} T_{\mathrm{ivc}}$ is mainly controlled by EVCtiming;however, the boost pressure also has a smaller effect on this parameter. Especially at advanced EVC, the temperature of residuals is higher than retarded $\mathrm{EVC}$, and the cooling effect of boosting is more distinct. When EVC was at $350^{\circ}$ CA ATDC, there was little difference in the temperature between the internal residuals and the fresh charge; thus, increasing the boost pressure almost had no effect on the mean temperature of the mixtures. 


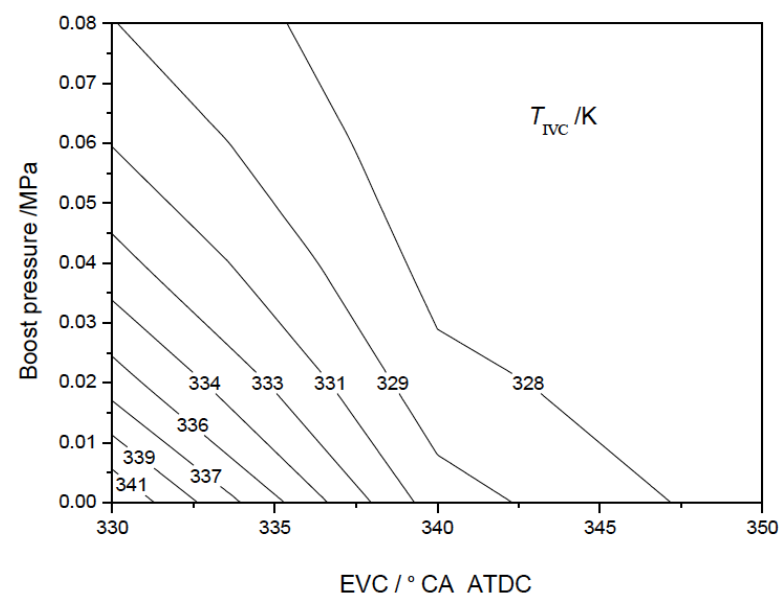

Fig. (4). Effects of EVC and boost pressure (gauge) on $T_{\text {ivc. }}$

\subsection{Effects of EVC and Supercharging on the Combus- tion Parameters}

\subsubsection{Effect of Supercharging on the Combustion Pressure and Heat Release Rate}

Compared with the boost pressure, EVC has a more distinct effect on the combustion phase. As observed in Fig. (5), retarding EVC can retard the start of combustion and decrease the heat release rate at different boost pressures because EVC determines the amount of internal residuals, which affects $T_{\mathrm{ivc}}$ and $\alpha$.

More importantly, over retarded EVC can only trap a few high-temperature residuals, which cannot supply enough thermal energy to vaporize diesel fuel. As Fig. (5) illustrates, the peak cylinder pressure at $\mathrm{EVC}=350^{\circ} \mathrm{CA}$ ATDC is much lower than that at $\mathrm{EVC}=330^{\circ} \mathrm{CA}$ ATDC at different boost pressures because of the sharp increase in fuel wall wetting.

\subsubsection{Effect of EVC on the Combustion Pressure and Heat Release Rate}

Fig. (6) plots the cylinder pressure and heat release rate as a function of the boost pressure(gauge) for three different EVC conditions. The cylinder pressure rapidly increased with the increase in boost pressure due to the increase in fresh charge. The combustion phase was retarded, and the heat release rate clearly decreased due to the effect of boosting on the excess air ratio and mean intake air temperature. A higherexcess air ratiomakes the mixture leaner, and the increasing cool charge decreases the mean temperature of the mixture, which both have the advantages of retarding the start of combustion and reducing the peak of the heat release rate.

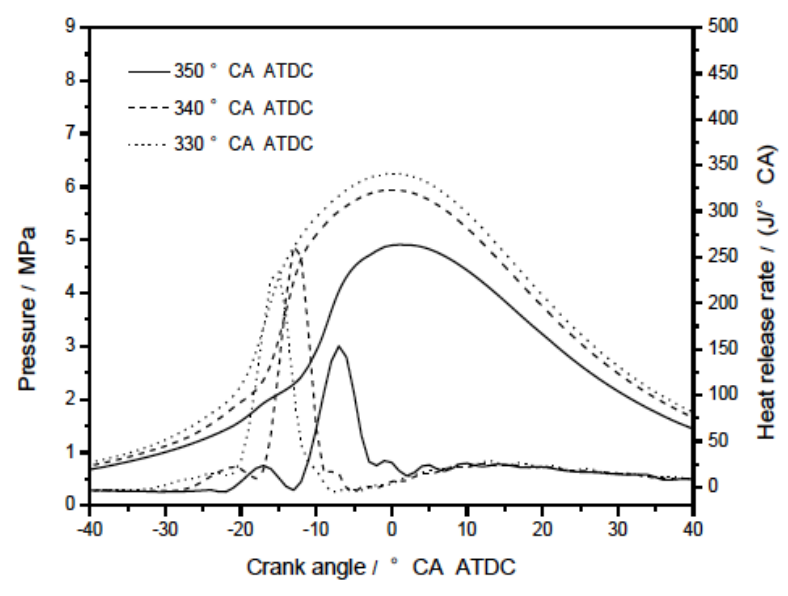

a) boost pressure $=0 \mathrm{MPa}$

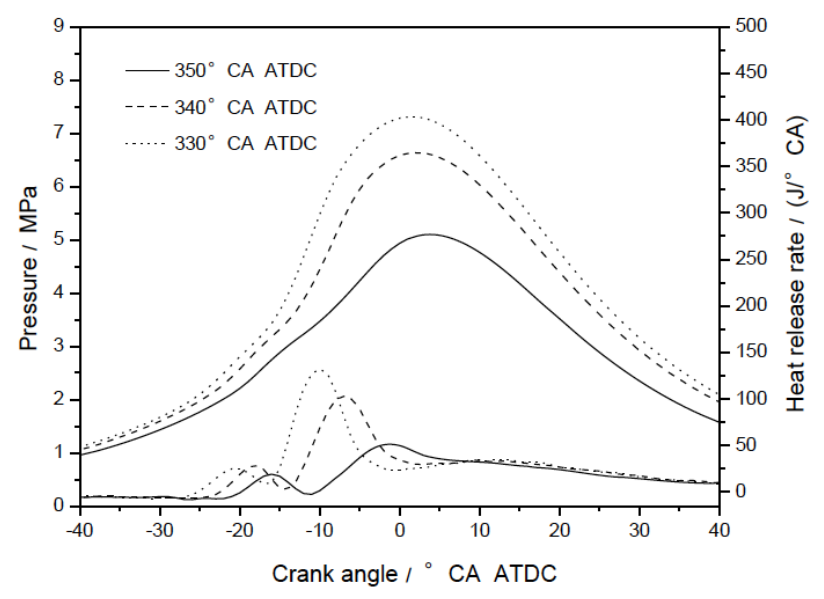

b) boost pressure $=0.04 \mathrm{MPa}$

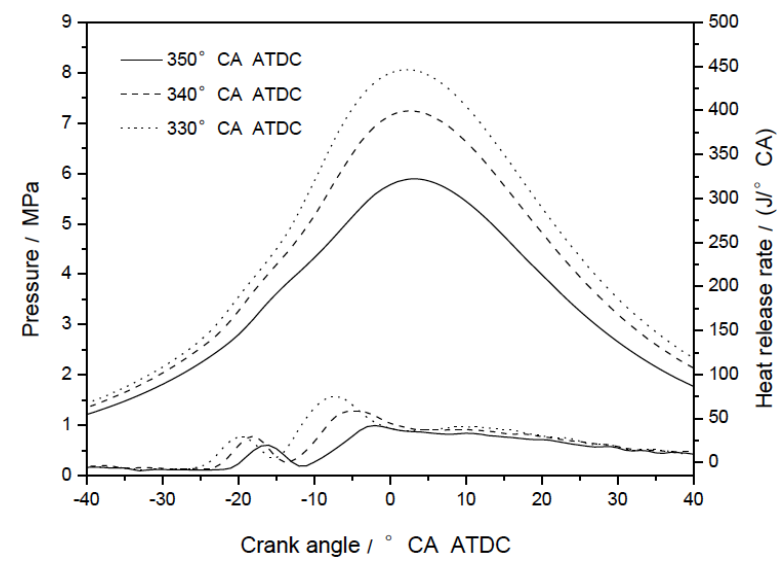

c) boost pressure $=0.08 \mathrm{MPa}$

Fig. (5). Effects of EVC on cylinder pressure and heat release rate at various boost pressures (gauge). 


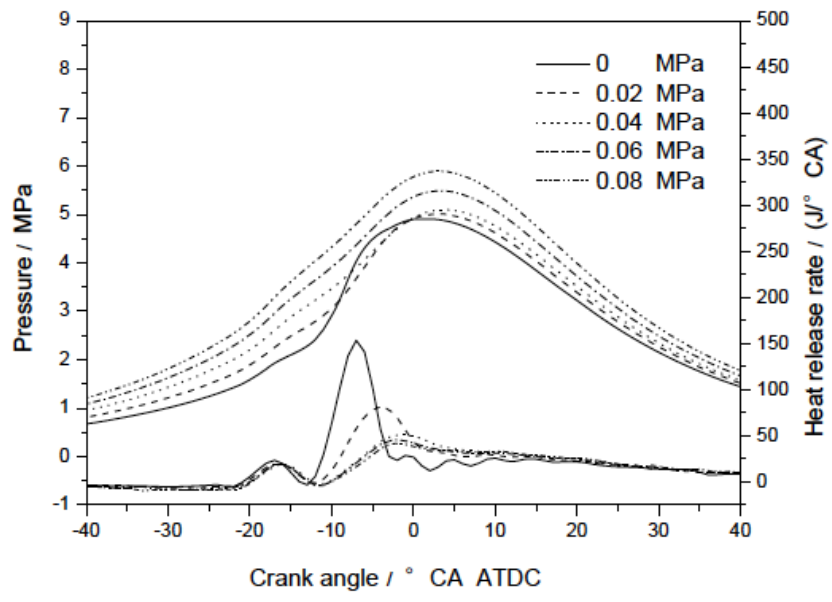

a) $\mathrm{EVC}=350^{\circ} \mathrm{CA} \mathrm{ATDC}$

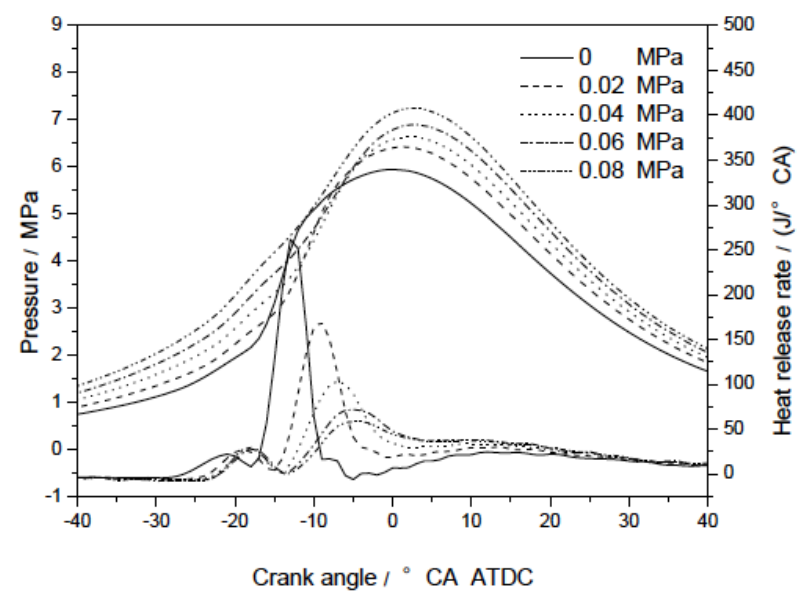

b) $\mathrm{EVC}=340^{\circ} \mathrm{CA} \mathrm{ATDC}$

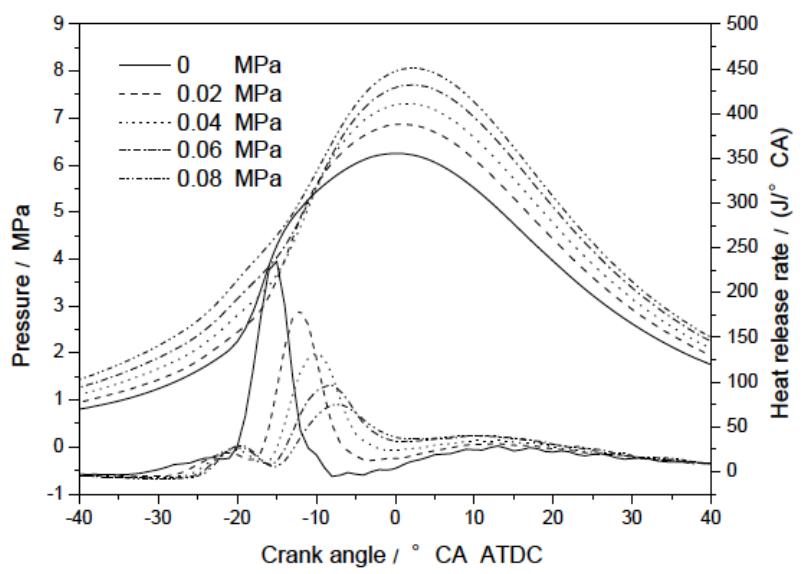

c) $\mathrm{EVC}=330^{\circ} \mathrm{CA} \mathrm{ATDC}$

Fig. (6). Effects of boost pressure (gauge) on cylinder pressure and heat release rate at various EVCs.

By changing the engine exhaust valve timing, a manageable quantity of internal residuals can be trapped in the cylinder. By tuning the quantity of residuals, the ignition delay and heat release rate of HCCI combustion can be adjusted. The main effect of residual gas on the HCCI combustion phase is thermal, which can advance the start of combustion.

\subsubsection{Effects of EVC and Supercharging on IMEPg and SOC}

Fig. (7) shows the effects of exhaust valve timing and boost pressure (gauge) on $\mathrm{IMEP}_{\mathrm{g}}$ and the start of combustion (SOC) (defined as the crank angle degree of cumulative HRR reaching $5 \%$ ). It can be observed that $\mathrm{IMEP}_{\mathrm{g}}$ of the EVC at $350^{\circ} \mathrm{CA}$ ATDC decreased as the boost pressure increased, and IMEP $_{\mathrm{g}}$ both of EVC at $340^{\circ} \mathrm{CA}$ ATDC and $330^{\circ} \mathrm{CA}$ ATDC increased at first and then decreased. Overall, $\mathrm{IMEP}_{\mathrm{g}}$ of the EVC at $350^{\circ} \mathrm{CA}$ ATDC was lower than that of EVC at $340^{\circ} \mathrm{CA}$ and $330^{\circ} \mathrm{CA}$ ATDC because the low RGF at EVC of $350^{\circ} \mathrm{CA}$ ATDC resulted in a low cylinder pressure. In addition, the fuel injected in the NVO period could not evaporate rapidly; thus, a large amount of fuel impingement occurred. The impingement resulted in a sharp decrease in the combustion efficiency. Increasing the boost pressure delayed the combustion phase and increased the combustion pressure but also decreased the combustion temperature. If the boost pressure was larger than the pressure corresponding to the maximum IMEP ${ }_{\mathrm{g}}, \mathrm{IMEP}_{\mathrm{g}}$ decreased as the boost pressure increased and decreased as the boost pressure decreased. Advancing EVC resulted in a more advanced combustion phase and was harmful for extending the engine load.

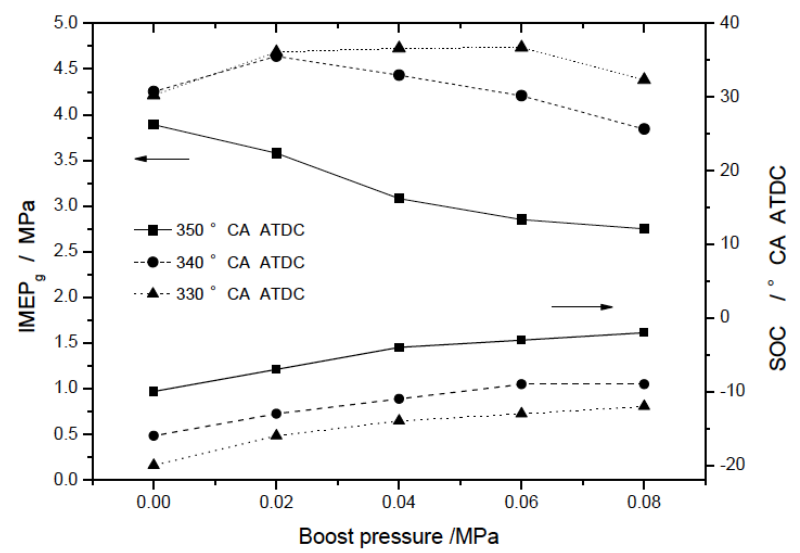

Fig. (7). Effects of EVC and boost pressure (gauge) on $\mathrm{IMEP}_{\mathrm{g}}$ and SOC. 


\subsubsection{Effects of NVO and Supercharging on the Maximum Pressure Rising Rate}

Fig. (8) shows the effects of NVO and supercharging on the maximum pressure rising rate. The results indicated that the maximum pressure rising rate increased gradually as EVC advanced and decreased gradually as the boost pressure increased. Because advancing the EVC degree advanced the combustion phase such that more fuel was combusted in a short time, the result was an increase in the maximum pressure rising rate. However, the increase in the boost pressure diluted the mixture such that the combustion became smooth and the peak of HRR decreased, which was beneficial for decreasing the maximum pressure rising rate.

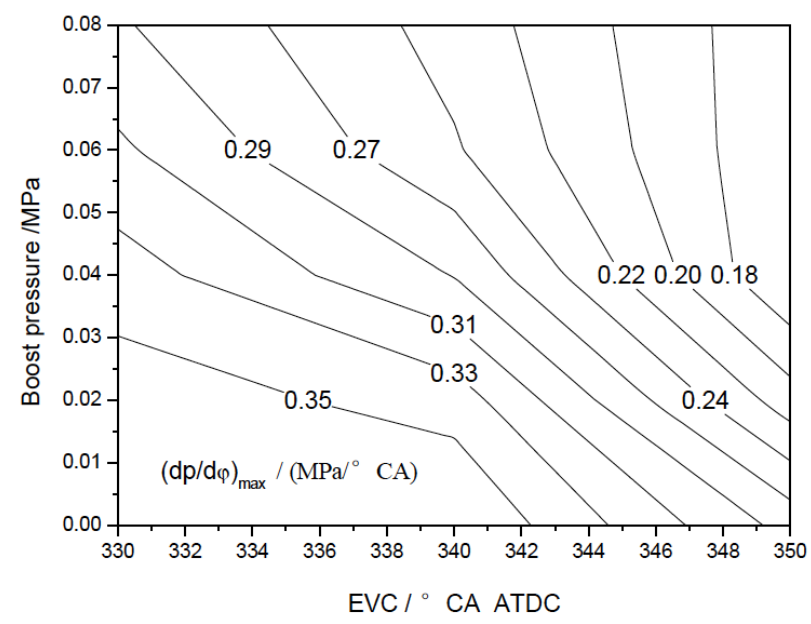

Fig. (8). Effects of EVC and boost pressure (gauge) on $\mathrm{dp} / \mathrm{d} \varphi_{\max }$

\subsection{Research on Load Extension of HCCI Combustion}

\subsubsection{Effect of NVO Duration on Load and Emissions of HCCI Combustion}

The high exhaust temperature produced by internal EGR can promote fuel evaporation and reduce fuel impingement; in addition, more internal EGR can also advance the start of combustion and lead to a higher cylinder pressure and pressure rising rate. Increasing the NVO duration caused more residuals to remain in the cylinder and enhanced the internal EGR. Therefore, in the research, the authors selected three different NVO durations of $20^{\circ} \mathrm{CA}, 30^{\circ} \mathrm{CA}$ and $40^{\circ} \mathrm{CA}$ to study the effects of NVO duration on internal EGR.

Fig. (9) (a) demonstrates how IMEP ${ }_{g}$ and ISFC are affected by the excess air ratio. The excess air ratio decreased from 3.32 to 2.82 , and $\mathrm{IMEP}_{\mathrm{g}}$ increased from $0.324 \mathrm{MPa}$ to $0.428 \mathrm{MPa}$ when NVO was $20^{\circ} \mathrm{CA}$. ISFC reached a minimum value of $223.3 \mathrm{~g} / \mathrm{kWh}$ when the excess air ratio was 2.82. Continuing to decrease the excess air ratio by increasing the fuel injection quantity after the minimum value caused the load to begin to decrease; the load range was approximately $0.104 \mathrm{MPa}$. At a high load, a low internal EGR rate was not sufficient to evaporate all the injected fuel, and further increasing the fuel injection quantity caused an increase in fuel impingement and a decrease in the combustion rate. When the NVO was $30^{\circ} \mathrm{CA}$, the decrease in excess air ratio caused IMEP $_{\mathrm{g}}$ to increase gradually from $0.287 \mathrm{MPa}$ to $0.445 \mathrm{MPa}$. Meanwhile the load range changed by 0.158
$\mathrm{MPa}$, which represented an increase of $0.054 \mathrm{MPa}$ compared with $20^{\circ} \mathrm{CA}$ NVO. The ISFC decreased to the minimum value of $205.8 \mathrm{~g} / \mathrm{kWh}$ and then began to increase slightly as the excess air ratio decreased. When the $\mathrm{NVO}$ was $40^{\circ} \mathrm{CA}$, more internal EGR helped evaporate more fuel, and promoted fuel and air mixing. Meanwhile IMEP ${ }_{g}$ could reach the maximum value of $0.484 \mathrm{MPa}$. In comparison, the smallest load range occurred at $20^{\circ} \mathrm{CA}$ NVO, the lowest low limit of the load range occurred at $30^{\circ} \mathrm{CA} \mathrm{NVO}$ and the highest high limit of the load range occurred at $40^{\circ} \mathrm{CA}$ NVO. However, as observed from $40^{\circ} \mathrm{CA}$ NVO, the NOx emission would increase sharply. Therefore, a gap of load remained between the HCCI combustion mode achieved using internal EGR and the traditional compression ignition mode, and the load range needs to be further extended using supercharging.

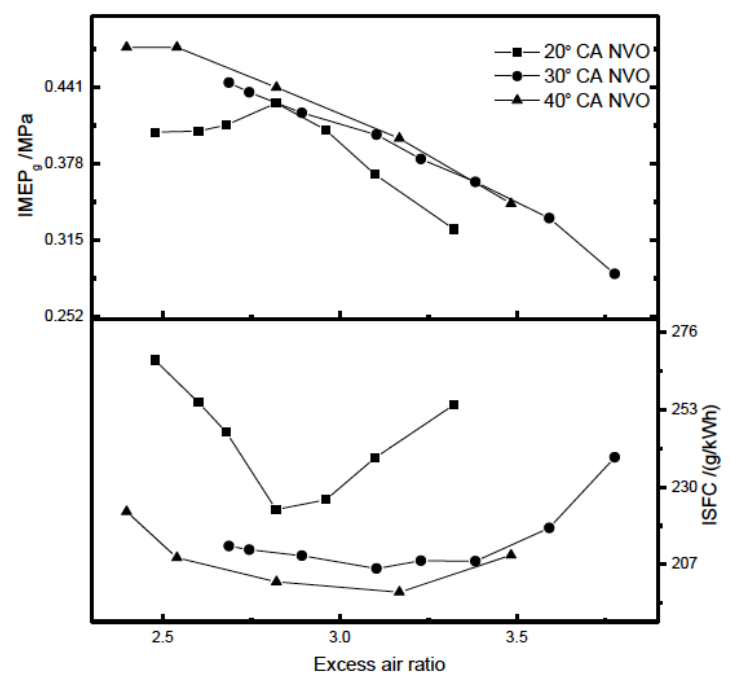

Fig. (9). (a) Effect of $\alpha$ on IMEP $_{g}$ and ISFC of HCCI Combustion at Various NVOs.

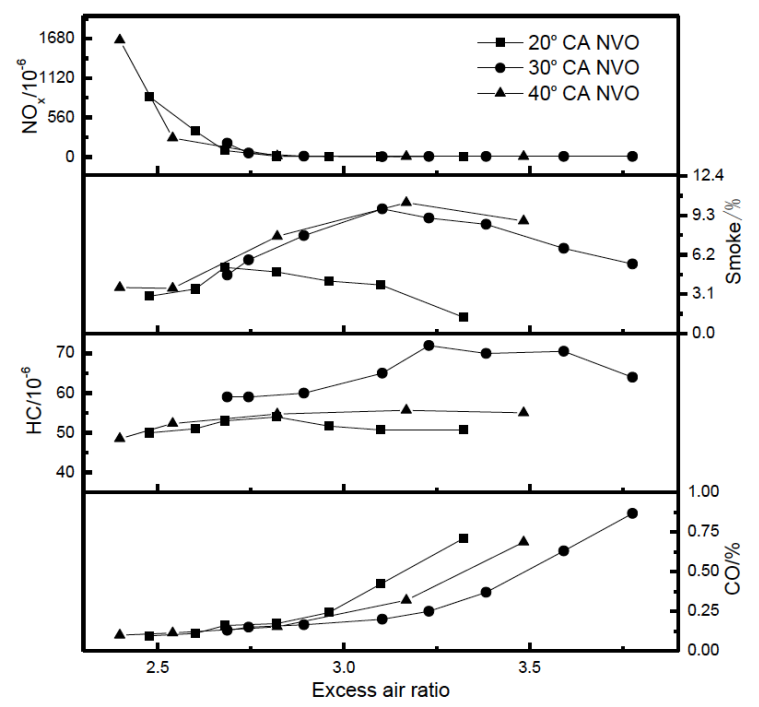

Fig. (9). (b) Effect of $\alpha$ on emissions of HCCI combustion for various NVOs.

Fig. (9) (b) shows the effect of the excess air ratio on emissions of HCCI combustion at various NVOs. The excess 
air ratio apparently affects the NOx emission of HCCI combustion because increasing the excess air ratio decreases the combustion temperature, which directly affects NOx generation. In the range that the excess air ratio changed from 2.5 to 2.8, the NOx emission decreased sharply; however, there was no obvious change of NOx emission after the excess air ratio exceeded 2.8, and the NOx emission value was less than $20 \times 10^{-6}$. When the excess air ratio was large, there was less fuel impingement and fuel and air mixing was sufficient; thus, the smoke emission was low. As the fuel injection per cycle increased, the excess air ratio decreased, and there was more fuel impingement; thus, the smoke emission was high. However, when we continued to increase the fuel injection, the increase of the combustion temperature benefitted the oxidation of smoke to reduce the smoke emission. Therefore, the change of smoke emission exhibited a trend that it increased at first and then decreased. There was no obvious change trend for $\mathrm{HC}$ emission; however, we observe that the $\mathrm{HC}$ emission at $30^{\circ} \mathrm{CA} \mathrm{NVO}$ was higher overall than that at $20^{\circ} \mathrm{CA}$ and $40^{\circ} \mathrm{CA}$ NVO. The $\mathrm{CO}$ emission increased with increasing excess air ratio because too low of a combustion temperature limited the further oxidation of $\mathrm{CO}$.

\subsubsection{Effect of Boost Pressure on Load and Emission of HCCI Combustion}

To further extend the load range of a diesel HCCI engine, the authors researched the effect of supercharging on the load and emissions by selecting three different intake pressures, $0.13 \mathrm{MPa}, 0.16 \mathrm{MPa}$ and $0.18 \mathrm{MPa}$, at $30^{\circ} \mathrm{CA} \mathrm{NVO}$. Fig. (10a) shows the effect of the excess air ratio on the load and emissions at various boost pressures. At the boost pressure of $0.13 \mathrm{MPa}$, the low limit and high limit of load were $0.469 \mathrm{MPa}$ and $0.601 \mathrm{MPa}$, respectively, both of which increased compared with the values without supercharging. When the boost pressure increased to $0.16 \mathrm{MPa}$, there was an obvious improvement in the load range. As the low load limit decreased to $0.378 \mathrm{MPa}$ and the high load limit increased to $0.675 \mathrm{MPa}$, the load range was as high as 0.297 $\mathrm{MPa}$. Upon further increasing the boost pressure to 0.18 $\mathrm{MPa}$, the low load limit further decreased to $0.27 \mathrm{MPa}$ and the high load limit further increased to $0.723 \mathrm{MPa}$; the load range was as high as $0.453 \mathrm{MPa}$.

Fig. (10b) presents the emission results at various boost pressures. When the excess air ratio exceeded 3, there was no obvious change in NOx emissions, and the value was less than $20 \times 10^{-6}$. The trend of smoke emissions continued to increase at first and then decreased as the excess air ratio decreased. However, with a continuous increase in the excess air ratio, the mixture was gradually diluted, the combustion temperature decreased and the combustion deteriorated; thus, both the $\mathrm{HC}$ and $\mathrm{CO}$ emissions increased.

\subsubsection{The Limit of Load Extension of HCCI}

The load extension of HCCI combustion is mainly limited by the maximum combustion pressure, maximum pressure rising rate and cycle-to-cycle variation of $\mathrm{IMEP}_{\mathrm{g}}$. The low load limit is determined by cycle-to-cycle variations of the load (COV of IMEP $_{\mathrm{g}}$ less than $8 \%$ ); the high load limit is determined by the maximum combustion pressure Pmax (less than $15 \mathrm{MPa}$ ) and the maximum pressure rising rate $(\mathrm{dp} / \mathrm{d} \varphi)_{\max }\left(\right.$ less than $\left.0.6 \mathrm{MPa} /{ }^{\circ} \mathrm{CA}\right)$.

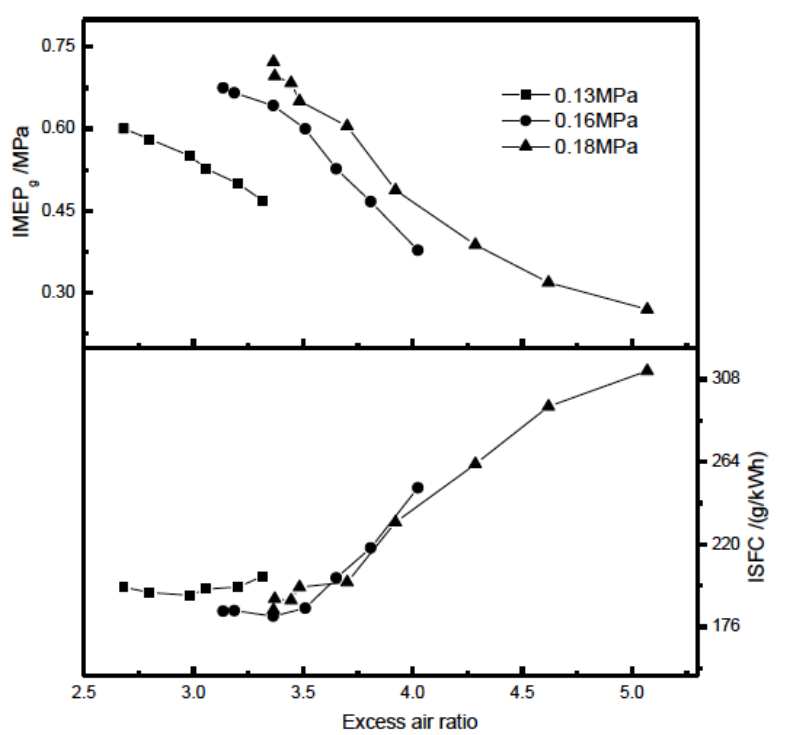

Fig. (10). (a) Effect of $\alpha$ on IMEP $_{\mathrm{g}}$ and ISFC of HCCI combustion at various boost pressures.

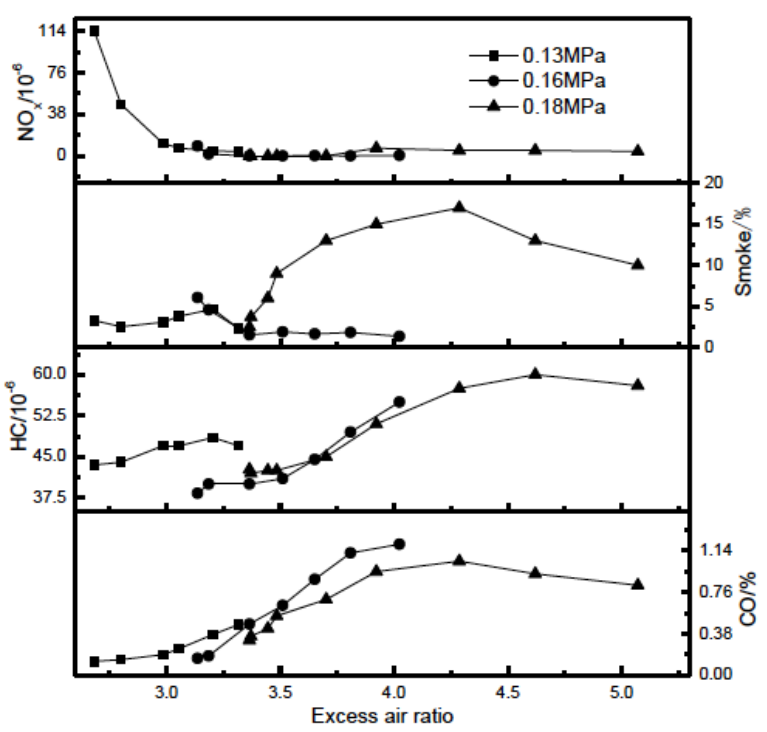

Fig. (10). (b) Effect of $\alpha$ on HCCI emission at various boost pressures.

Fig. (11) shows the effect of the excess air ratio on the load extension limit under various NVOs. Pmax and $(\mathrm{dp} / \mathrm{d} \varphi)_{\max }$ had a linear relationship with the excess air ratio, and both of these parameters reached their maximum values when the excess air ratio was the lowest. With an increasing amount of dilution mixing gas, it is easier to misfire and more unstable for combustion; thus, COV increased with the increase in the excess air ratio. Under a low excess air ratio, the effect of NVO on the load extension limit was not obvious.

Fig. (12) shows variations of the load range limit with the change of excess air ratio at various boost pressures. Upon increasing the boost pressure, Pmax increased obviously. At a boost pressure of $0.18 \mathrm{MPa}$, the excess air ratio varied from 3.36 to 5.07 , which was the widest range, and misfire occurred when the excess air ratio exceeded the maximum 
value of 5.07.Under the lowest excess ratio, Pmax could reach $10.02 \mathrm{MPa}$, and no clear increase in $(\mathrm{dp} / \mathrm{d} \varphi)_{\max }$ was apparent with the highest value of $0.579 \mathrm{MPa} /{ }^{\circ} \mathrm{CA}$. At the boost pressure of $0.13 \mathrm{MPa}$, the excess air ratio varied from 2.68 to 3.32 , which was the narrowest range, and misfire occurred similarly when the excess air ratio exceeded the maximum value of 3.32. Pmax could only reach $8.25 \mathrm{MPa}$; however, $(\mathrm{dp} / \mathrm{d} \varphi)_{\max }$ was at the highest level, approximately $0.631 \mathrm{MPa} /{ }^{\circ} \mathrm{CA}$. Compared with the two different boost pressures, it can be observed that the misfire range of the excess air ratio increased with an increase in the boost pressure.

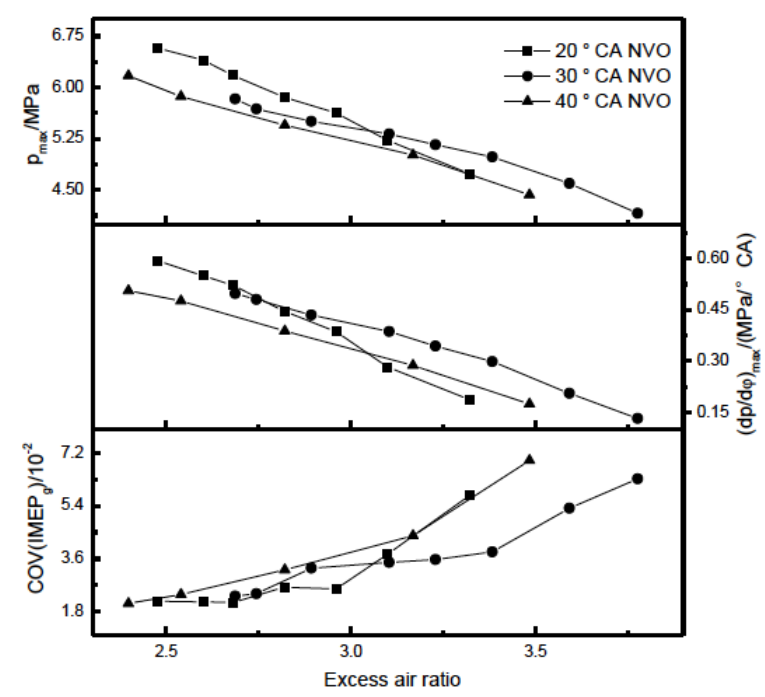

Fig. (11). Effect of excess air ratioon HCCI Limit at various NVOs.

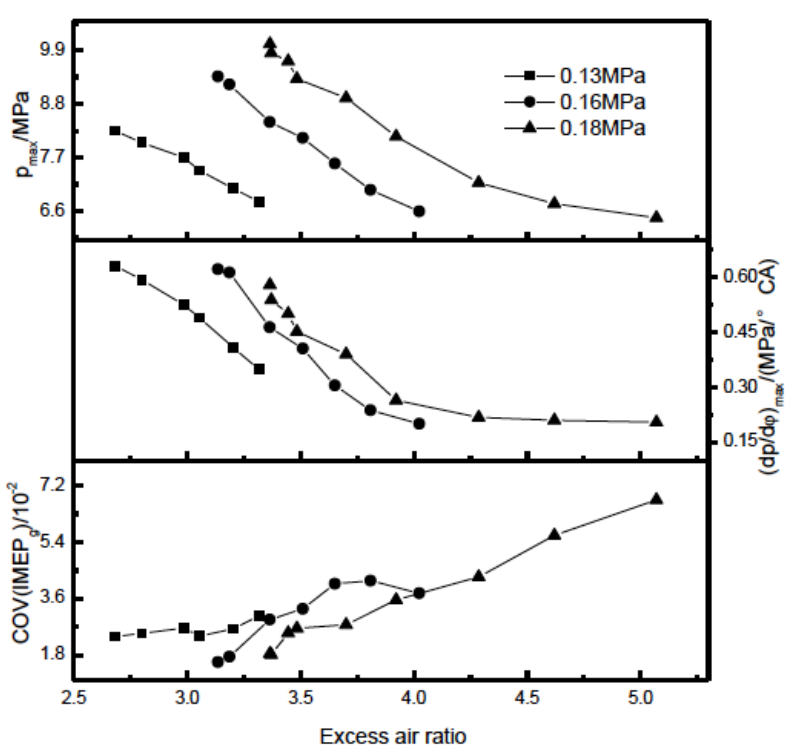

Fig. (12). Effect of excess air ratioon HCCI limit at various boost pressures.

\section{CONCLUSION}

The following conclusions were drawn from the experimental results.
At $1500 \mathrm{r} / \mathrm{min}$ in the HCCI combustion mode, the engine can achieve optimum fuel economy when the start of injection is at $370^{\circ} \mathrm{CA}$ BTDC. For constant fuel injection per cycle, the maximum combustion pressure increases, the peak of HRR increases and the combustion phase advances as the NVO duration increases. As the intake pressure increases, the maximum combustion pressure decreases, the peak of HRR decreases and the combustion phase is postponed when the NVO duration increases for constant fuel injection per cycle.

A reasonable internal EGR strategy can extend the load range of HCCI combustion. A large NVO or internal EGR can promote fuel evaporation but also leads to a high combustion temperature, which is harmful to NOx emission. If the NVO or internal EGR is small, serious fuel impingement occurs at a high load. Therefore, selecting $30^{\circ} \mathrm{CA}$ NVO for the research was reasonable.

The load extension is mainly limited by the maximum combustion pressure, maximum pressure rising rate and cycle-to-cycle variation of IMEP. These parameters are all relevant to the excess air ratio. As the excess air ratio decreases, the maximum combustion pressure and maximum pressure rising rate increase. As the excess air ratio increases, the cycle-to-cycle variation of IMEP $_{g}$ increases and the engine becomes easier to misfire. In the research on load extension realized by combining internal EGR with supercharging, the high load limit depends on the maximum pressure rising rate, and the low load limit depends on the cycleto-cycle variation of IMEP $_{\mathrm{g}}$.

Supercharging can extend the high load limit of HCCI combustion and enhance combustion stability at low loads. At $1500 \mathrm{r} / \mathrm{min}, 30^{\circ} \mathrm{CA} \mathrm{NVO}$, and $0.18 \mathrm{MPa}$ boost pressure, the low load limit and high load limit of HCCI combustion reached $0.27 \mathrm{MPa}$ and $0.723 \mathrm{MPa}$, respectively.

\section{CONFLICT OF INTEREST}

The authors confirm that this article content has no conflict of interest.

\section{ACKNOWLEDGEMENTS}

This research was supported by the National Natural Science Foundation of China (Grant No.51106098). The authors are grateful to their colleagues at the Center for Combustion and Environmental Technology of Shanghai Jiao Tong University.

\section{REFERENCES}

[1] M. A. Ceviz, A. K. Sen, A. K. Kuleri, and I. V. Oner, "Engine performance, exhaust emissions, and cyclic variations in a leanburn SI engine fueled by gasoline-hydrogen blends," Applied Thermal Engineering, vol. 36, pp. 314-324, 2012.

[2] H. Wu, N. Collings, S. Regitz, J. Etheridge, and M. Kraft, "Experimental investigation of a control method for SI-HCCI-SI transition in a multi-cylinder gasoline engine," SAE paper 2010-01$1245,2010$.

[3] A. P. Carlucci, D. Laforgia, S. Motz, R. Saracino, and S. P. Wenzel, "Advanced closed loop combustion control of a LTC diesel engine based on in-cylinder pressure signals," Energy Conversion and Management, vol. 77, pp.193-207, 2014.

[4] X.C. Lu, D. Han, and Z. Huang, "Fuel design and management for the control of advanced compression-ignition combustion modes," 
Progress in Energy and Combustion Science, vol. 37, pp. 741-783, 2011.

[5] B. M. Knight, J. A. Bittle, and T. J. Jacobs, "Characterizing the influence of EGR and fuel pressure on the emissions in low temperature diesel combustion," SAE paper 2011-01-1354, 2011.

[6] U.Asad, and M.Zheng, "Efficiency \& stability improvements of diesel low temperature combustion through tightened intake oxygen control," SAE paper 2010-01-1118, 2010.

[7] Q. Fang, J. Fang, J. Zhuang, and Z. Huang, "Influences of pilot injection and exhaust gas recirculation (EGR) on combustion and emissions in a HCCI-DI combustion engine," Applied Thermal Engineering, vol. 48, pp. 97-104, 2012.

[8] R. K. Maurya, and A. K. Agarwal, "Statistical analysis of the cyclic variations of heat release parameters in HCCI combustion of methanol and gasoline," Applied Energy, vol. 89, pp. 228-236, 2012.

[9] A. W. Berntsson, M. Andersson, D. Dahl, and I. Denbratt, "A LIFstudy of $\mathrm{OH}$ in the negative valve overlap of a spark-assisted HCCI combustion engine," SAE paper 2008-01-0037, 2008.

[10] C. Wildman, R. J. Scaringe, and W. Cheng, "On the maximum pressure rise rate in boosted HCCI operation," SAE paper 2009-01$2727,2009$.
[11] Weall, J. P. Szybist, and K. D. Edwards, "HCCI load expansion opportunities using a fully variable HVA research engine to guide development of a production intent cam-based VVA engine: the low load limit," SAE paper 2012-01-1134,2012.

[12] J. Hunicz, and P. Kordos, "An experimental study of fuel injection strategies in CAI gasoline engine," Experimental Thermal and Fluid Science, vol. 35, pp. 243-252, 2011.

[13] J. Hunicz, "An experimental study of negative valve overlap injection effects and their impact on combustion in a gasoline HCCI engine," Fuel, vol. 117, pp. 236-250, 2014.

[14] L. Shi, K. Deng, and Y. Cui, "Study of diesel-fueled HCCI combustion by in-cylinder early fuel injection and negative valve overlap, "Journalof Automobile Engineering, Proceedings of the IMechE Part D, vol. 219, 10, pp. 1193-1201, 2005.

[15] Z. Peng, and M. Jia, "CFD analysis of VVT/VVA on the gas exchange and fuel-air mixing in a diesel engine," SAE paper 2008$01-1635,2009$.

[16] S. Han, E. Shim, J. Jang, J. Park, and C. Bae, "Operating range of low temperature diesel combustion with supercharging," SAE paper 2009-01-1440, 2009.

Received: February 03, 2015

Revised: April 03, 2015

Accepted: May 25, 2015

(C) Sun et al.; Licensee Bentham Open.

This is an open access article licensed under the terms of the (https://creativecommons.org/licenses/by/4.0/legalcode), which permits unrestricted, noncommercial use, distribution and reproduction in any medium, provided the work is properly cited. 